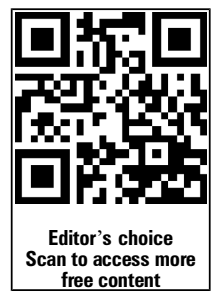

free content

\title{
Salbutamol or aminophylline for acute severe asthma: how to choose which one, when and why?
}

\author{
Matthew Neame, ${ }^{1}$ Octavio Aragon, ${ }^{2}$ Ricardo M Fernandes, ${ }^{3,4}$ Ian Sinha ${ }^{1}$
}

- Additional material is published online only. To view please visit the journal online (http://dx.doi.org/10.1136/ archdischild-2014-306186).

${ }^{1}$ Department of Respiratory Medicine, Alder Hey Children's Hospital, Liverpool, UK ${ }^{2}$ Department of Pharmacy, Alder Hey Children's Hospital, Liverpool, UK

${ }^{3}$ Department of Pediatrics, Hospital Santa Maria, Lisbon Academic Medical Centre, Lisbon, Portugal

${ }^{4}$ Clinical Pharmacology Unit, Instituto de Medicina Molecular, University of Lisbon, Lisbon, Portugal

\section{Correspondence to} Dr lan Sinha, Department of Respiratory Medicine, Alder Hey Children's Hospital, Eaton Road, Liverpool L12 2AP, UK; I.Sinha@liverpool.ac.uk

Received 25 June 2014 Revised 18 November 2014 Accepted 2 December 2014 Published Online First

13 January 2015

\section{CrossMark}

To cite: Neame M,

Aragon O, Fernandes RM,

et al. Arch Dis Child Educ

Pract Ed 2015;100:215-222.

\begin{abstract}
Acute, severe exacerbations of asthma present a challenge due to the significant morbidity associated with this presentation. For exacerbations that are refractory to initial treatments with inhaled and oral therapies, there is still doubt about which intravenous therapies are most likely to be helpful. $\beta-2$ agonists and aminophylline have differing mechanisms of action that also affect their adverse effects profiles and these are considered. A review of the available randomised control trials suggests that a bolus of intravenous salbutamol may reduce symptoms and hasten recovery. Aminophylline infusions may improve lung function, and in some studies have been shown to improve symptoms, but the evidence is not clear cut. Decisions about which treatment to use should include risk management considerations such as ease of prescription, preparation and administration factors and availability of high-dependency beds.
\end{abstract}

\section{INTRODUCTION}

The pathophysiology of asthma exacerbations is complex. Exposure to a trigger induces a complex interplay of factors, including eosinophil and mast cell degranulation and epithelial damage. These cause histamine, prostaglandin and leukotriene release. Continuing $\mathrm{T}$ cell and $\mathrm{B}$ cell differentiation and proliferation, promoted by cytokine release, perpetuate this cascade. Subsequent inflammation, bronchoconstriction and mucus production cause airway obstruction and impairment of gas exchange. ${ }^{1}$

Although most children improve after inhaled bronchodilator by nebuliser or spacer, some require intravenous treatment. Magnesium sulfate is often used as the first-line intravenous therapy for such children. $^{2}$ In children who require additional intravenous therapy, salbutamol and aminophylline are used in practice, but there is no clear consensus around which should be used first. ${ }^{3}$ In this paper, we aim to summarise the pharmacological basis of these agents and evidence from randomised controlled trials (RCTs) relating to their efficacy and safety.

\section{PHARMACOLOGY OF B-2 AGONISTS}

Salbutamol and terbutaline are similar $\beta-2$ adrenoceptor agonists that are believed to exert their maximal therapeutic effect through bronchodilation. Stimulation of $\beta-2$ receptors in airway smooth muscle induces the cyclic AMP (c-AMP) pathway. c-AMP is a molecule with various cellular functions. Increased activity of c-AMP-dependent protein kinase A inhibits myosin phosphorylation and lowers intracellular calcium concentration, which in turn relaxes smooth muscle and causes bronchodilation. ${ }^{4}$ Increased intracellular c-AMP may also inhibit mast cell inflammatory mediator release (figure 1 ; adapted from refs. 5 and 6). Severe airway obstruction may restrict delivery of inhaled salbutamol to the airway epithelium, thus providing a theoretical rationale for the use of intravenous preparations. Because adrenoreceptors are found in various organs and tissues, $\beta-2$ agonists can also cause various extrapulmonary adverse effects.

\section{Pharmacokinetics}

The half-life of salbutamol is 4-6 h, and it is excreted renally. The bronchodilatory effects of salbutamol are believed to occur at blood concentrations of between 5 and $20 \mathrm{ng} / \mathrm{mL}$, and higher concentrations are thought to result in a greater risk of toxicity. There are limited data regarding the ideal dosing schedule for intravenous salbutamol in children. 


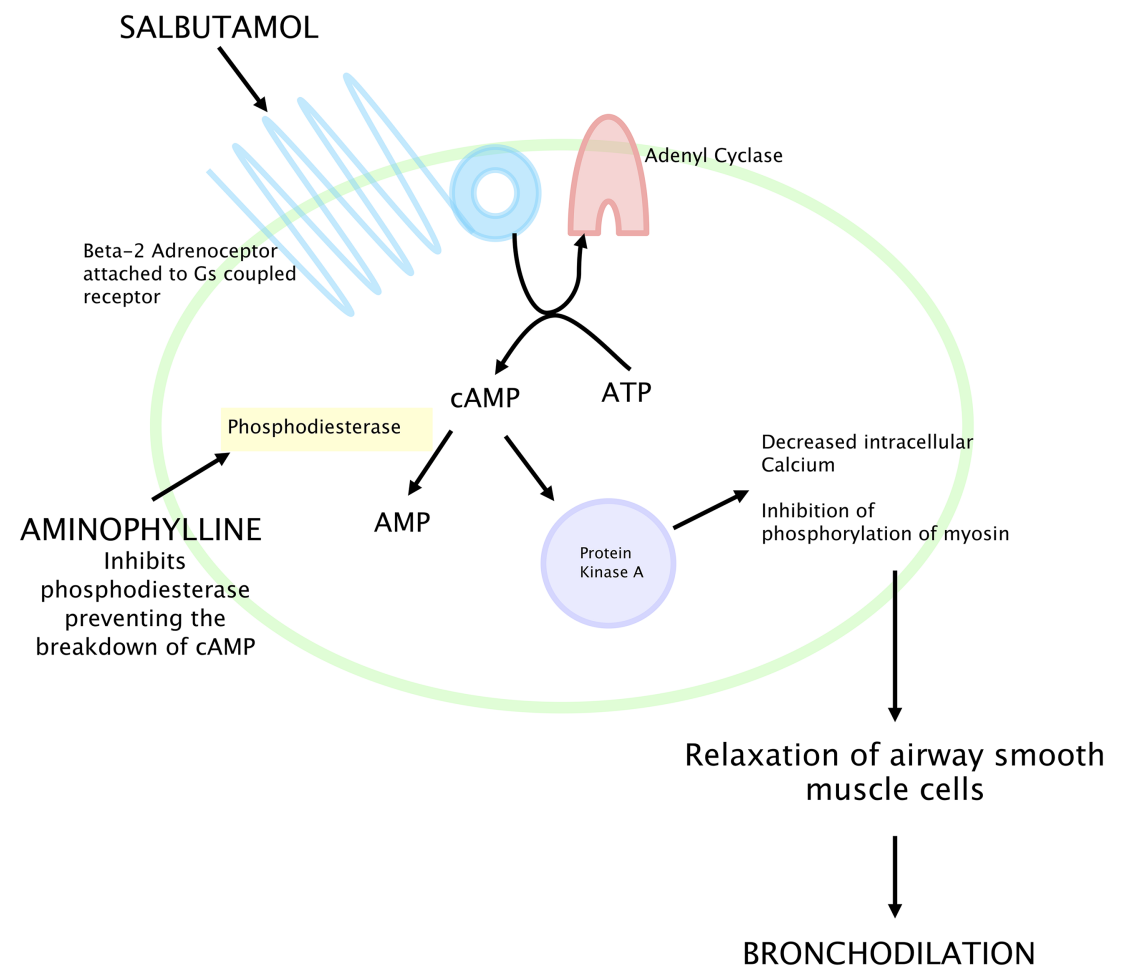

Figure 1 An illustration of the mechanisms by which salbutamol and aminophylline may cause bronchodilation through increasing intracellular cyclic AMP levels.

A recent review commented on the relatively high doses per unit of weight advised for use in children compared with adult regimens and recommended further research into the pharmacodynamics and pharmacokinetics of intravenous salbutamol in the paediatric population. ${ }^{7}$

\section{Cardiovascular effects}

Salbutamol stimulates both $\beta-1$ and $\beta-2$ receptors in the heart and can reduce afterload through vasodilation and a drop in vascular resistance. ${ }^{8} 9$ These effects can cause significant tachycardia, postural hypotension and myocardial ischaemia.

\section{Muscle tremors}

Stimulation of $\beta-2$ receptors in skeletal muscle may cause tremors, which can be uncomfortable for children.

\section{Metabolic effects of $\boldsymbol{\beta}-\mathbf{2}$ agonists}

$\beta-2$ agonists can cause hypokalaemia, in a dosedependent fashion, because $\beta-2$ receptors are linked to membrane bound $\mathrm{Na}^{+} / \mathrm{K}^{+}$ATPase pumps. They can stimulate $\beta-2$ receptors in both pancreatic islet cells and hepatocytes, causing increased insulin secretion (which can exacerbate hypokalaemia) and increased glycogenolysis, respectively. ${ }^{10} 11$ Patients treated with intravenous salbutamol may develop lactic acidosis because of $\beta$-2-stimulated anaerobic glycolysis in muscle. This has been demonstrated in healthy subjects ${ }^{12}$ and has been observed in asthmatic individuals. ${ }^{13} 14$ There are reports of the subsequent metabolic acidosis contributing to a perception of increased respiratory distress with a concomitant and unnecessary treatment escalation or continuation. There do not seem to be reports of the lactic acidosis having any directly harmful consequences.

\section{Tolerance}

There is evidence that regular use of inhaled $\beta-2$ agonists can modify the response of the $\beta-2$ receptor resulting in reduced efficacy. ${ }^{15}$ This may make the use of intravenous salbutamol less beneficial in some cases, but the clinical significance of this finding in the management of acute exacerbations of asthma remains unclear.

\section{PHARMACOLOGY OF AMINOPHYLLINE}

Aminophylline is a methylated xanthine derivative. It is a combination of theophylline (the active component) and ethylenediamine, which is a compound that increases the solubility of theophylline but has no known intrinsic pharmacological effects.

The mechanisms of action of aminophylline are not completely understood. Beneficial effects may result from both bronchodilation and reduced airway hypersensitivity, but the extent to which each mechanism confers benefit at therapeutic doses is unclear. ${ }^{16} 17$ Effective use of the drug also requires a consideration of its pharmacokinetics

\section{Pharmacokinetics}

Aminophylline has a narrow therapeutic range, and the associations between elevated levels and unwanted effects are important to consider. The bronchodilator 
Table 1 A comparison of factors affecting prescription, administration and monitoring when using intravenous aminophylline and intravenous salbutamol infusions and boluses ${ }^{\text {W20-25 }}$

\begin{tabular}{|c|c|c|c|c|}
\hline & & Aminophylline & Salbutamol infusion & Salbutamol bolus \\
\hline \multirow[t]{7}{*}{$\begin{array}{l}\text { Administration } \\
\text { details }\end{array}$} & $\begin{array}{l}\text { Reconstitution } \\
\text { Dilution }\end{array}$ & $\begin{array}{l}\text { - No, solution } \\
\text { Yes: suggested concentrations } 1 \mathrm{mg} / \mathrm{mL} \\
\text { Has been used neat ( } 25 \mathrm{mg} / \mathrm{mL} \text { ) in fluid restriction } \\
\text { (central line preferred as highly irritant) }\end{array}$ & $\begin{array}{l}\text { - No, solution } \\
\text { - Yes, suggested concentration of } 200 \mu \mathrm{g} / \mathrm{mL} \text { for central line and } 10-20 \mu \mathrm{g} / \\
\mathrm{mL} \text { for peripheral line } \\
\text { - Has been used neat }(1 \mathrm{mg} / \mathrm{mL} \text { ) in fluid restriction (central line only) }\end{array}$ & $\begin{array}{l}\text { - No, solution } \\
\text { Yes, suggested concentration of } \\
200 \mu \mathrm{g} / \mathrm{mL} \text { for central line and } \\
10-20 \mu \mathrm{g} / \mathrm{mL} \text { for peripheral line } \\
\text { - Has been used neat ( } 1 \mathrm{mg} / \mathrm{mL} \text { ) in fluid } \\
\text { restriction (central line only) }\end{array}$ \\
\hline & $\begin{array}{l}\text { Calculation } \\
\text { complexity }\end{array}$ & - Yes: multistep calculation for dilution and rate & $\begin{array}{l}\text { - Yes: multistep calculation for dilution and rate } \\
\text { Conversion between milligrams and micrograms } \\
\text { - Conversion between hours and minutes }\end{array}$ & $\begin{array}{l}\text { Yes: multistep calculation for dilution } \\
\text { and rate } \\
\text { - Conversion between milligrams and } \\
\text { micrograms }\end{array}$ \\
\hline & $\begin{array}{l}\text { Therapeutic risk } \\
\text { Need to use part } \\
\text { vials }\end{array}$ & $\begin{array}{l}\text { High: narrow therapeutic index drug } \\
\text { Yes: for loading dose } \\
\text { oes/no: for maintenance infusion depending } \\
\text { on house recommendations }\end{array}$ & $\begin{array}{l}\text { High } \\
\text { Yes } \\
\text { Also for larger patients need to use multiple vials to avoid multiple bag } \\
\text { changes }\end{array}$ & $\begin{array}{l}\text { High } \\
\text { Yes }\end{array}$ \\
\hline & $\begin{array}{l}\text { Different } \\
\text { strengths } \\
\text { available }\end{array}$ & - No & - Yes & - Yes \\
\hline & $\begin{array}{l}\text { Need for infusion } \\
\text { pump }\end{array}$ & - Yes & - Yes & - Yes \\
\hline & Other & $\begin{array}{l}\text { - Loading dose and maintenance rate will have } \\
\text { different rates and potentially different } \\
\text { concentrations } \\
\text { Stable for } 24 \mathrm{~h} \text { once dilutes }\end{array}$ & $\begin{array}{l}\text { - Protect from light } \\
\text { Stable for } 24 \mathrm{~h} \text { once diluted }\end{array}$ & $\begin{array}{l}\text { - Protect from light } \\
\text { - Stable for } 24 \mathrm{~h} \text { once diluted }\end{array}$ \\
\hline & Risk score & Amber: moderate risk & - Amber: moderate risk & - Amber: moderate risk \\
\hline \multirow[t]{2}{*}{$\begin{array}{l}\text { Fluid } \\
\text { compatibility }\end{array}$} & Additive & $\begin{array}{l}\text { Sodium chloride } 0.9 \% \text { and } 0.45 \% \\
\text { Dextrose } 5 \% \\
\text { Combination of the above } \\
\text { Combination of the above with up to } 20 \mathrm{mmol} / \\
500 \mathrm{~mL} \text { of potassium chloride }\end{array}$ & $\begin{array}{l}\text { Sodium chloride } 0.9 \% \text { and } 0.45 \% \\
\text { Dextrose } 5 \% \\
\text { Combination of the above }\end{array}$ & $\begin{array}{l}\text { Sodium chloride } 0.9 \% \text { and } 0.45 \% \\
\text { Dextrose } 5 \% \\
\text { Combination of the above }\end{array}$ \\
\hline & Y-site & $\begin{array}{l}\text { - As above } \\
\text { - Aminophylline is alkaline (avoid acidic drugs) }\end{array}$ & $\begin{array}{l}\text { - As above } \\
\text { - Salbutamol is acidic (avoid alkaline drugs) }\end{array}$ & $\begin{array}{l}\text { - As above } \\
\text { - Salbutamol is acidic (avoid alkaline } \\
\text { drugs) }\end{array}$ \\
\hline \multirow[t]{2}{*}{ Monitoring } & Levels & $\begin{array}{l}\text { Yes } \\
30 \text { min after completion of loading dose } \\
\text { At least daily thereafter } \\
\text { (6-12 h after rate changes) }\end{array}$ & - No & - No \\
\hline & U\&ES & - Yes: potassium at least daily & $\begin{array}{l}\text { Yes: potassium, recommended twice daily } \\
\text { - Yes: blood glucose, recommended twice daily }\end{array}$ & $\begin{array}{l}\text { Yes: potassium } \\
\text { - Yes: blood glucose }\end{array}$ \\
\hline
\end{tabular}




\begin{tabular}{lll} 
& Aminophylline \\
\hline ECG & Yes: during loading dose \\
& & Often continues during maintenance infusion \\
& & HDU bed recommended if available (administration \\
Prescription ease & Bould not be delayed if unavailable) \\
& & Varies with age \\
& & Calculate and prescribe different doses for loading \\
& dose and maintenance infusion: use standard \\
& concentration recommended \\
& 2 prescriptions, one for loading dose, one for \\
& maintenance infusion
\end{tabular}

- No blind loading dose recommended for patient on theophylline therapies at home or with renal/ liver impairment

- Cap loading dose at $500 \mathrm{mg}$

- Adjust rates depending on levels and side effects

Drug particulars

- High metabolic interaction risk - Aciclovir, azole antifungals, macrolides, quinolones, calcium channel blockers, etc., will raise theophylline concentrations

- Some antiepileptics, rifampicin, tobacco smoke will reduce theophylline concentrations

- Additive hypokalaemia with common concomitant treatments (steroids, salbutamol)

- Pharmacokinetics vary greatly with age:

- Neonates and infants under 6 months slower

clearance than adults

- Infants and children up to 9-10 faster clearance than adults

- Gender different clearance in adolescents

- Requires pharmacy input for dosage adjustments, how long to stop, how much to re-load with etc

Licensing

- Licensed in children older than 6 months

- Licensed for children older than 12 years

- Licensed for children older than 12 years

Salbutamol bolus

- May be given in A\&E

BP and heart rate

- Varies with age

Vast range of doses: $0.1-10 \mu \mathrm{g} / \mathrm{kg} / \mathrm{min}$. (Although note that when prescribing for children the maximum adult dose suggested in the BNF of $20 \mu \mathrm{g} / \mathrm{min}$ will often be surpassed. A total dose cap should be considered for larger children)

Conversion mg-micrograms

Conversion hours-minutes

- Difficult to use a standard concentration due to variability in doses

- Adjust rates depending on clinical picture and side effects
- Low metabolic interaction risk - Antidiabetic agents

- Additive hypokalaemia with common concomitant treatments (steroids, aminophylline)
- Set dose (may be repeated if needed)

- Cap dose at $250 \mu \mathrm{g}$

Over 5-20 min
Low metabolic interaction risk - Antidiabetic agents

- Additive hypokalaemia with common concomitant treatments (steroids, aminophylline) 
effects of theophylline are proportional to the log of its concentration-in other words, increasing theophylline plasma concentration causes a less than proportional increase in bronchodilation, such that levels higher than $20 \mathrm{mg} / \mathrm{L}$ are unlikely to offer additional therapeutic benefit but will increase the risk of toxicity. Furthermore, clearance rates are affected by factors including age and the use of cytochrome P450 inducers and inhibitors. This makes careful dosing and regular assessments of serum theophylline levels crucial.

\section{Mechanism of bronchodilation}

Aminophylline may cause bronchodilation through effects on c-AMP by inhibiting certain phosphodiesterase enzymes (figure 1). Phosphodiesterases degrade intracellular c-AMP molecules, so their inhibition may result in increased levels of intracellular c-AMP and subsequent airway smooth muscle relaxation. ${ }^{18}$ Interestingly, however, the degree of phosphodiesterase inhibition is not particularly significant at therapeutically relevant theophylline concentrations. ${ }^{19}$ Furthermore, other drugs that inhibit phosphodiesterases more significantly are not thought to have significant bronchodilator effects at therapeutic doses (ie, roflumilast, cilomilast). Other hypotheses around the bronchodilator effects of aminophylline are that it can act by blocking adenosine receptors (adenosine has little effect on human airway muscle in vitro but can cause bronchoconstriction in asthmatic subjects when given by inhalation) and that it induces catecholamine release with subsequent adrenergic stimulation. ${ }^{20}$ It is possible, therefore, that aminophylline acts on more pathways than salbutamol.

\section{Immunomodulation}

Other benefits in asthma exacerbations may relate to immunomodulation and anti-inflammatory effects. Long-term use of oral theophylline can reduce the numbers and activity of eosinophils in bronchial mucosa. ${ }^{21}$ Aminophylline might also exert anti-inflammatory effects by enhancing neutrophil apoptosis via adenosine receptor antagonism ${ }^{22}$ or by inhibiting histones required for activation of inflammatory gene transcription. ${ }^{23}$ These effects can occur at low or subtherapeutic plasma theophylline concentrations.

\section{Seizures}

In case series, aminophylline has been implicated in the development of seizures in children, some of whom have not had underlying epilepsy, and in some cases theophylline levels remained within the recommended therapeutic range. ${ }^{24-26}$ Although the mechanism for this is unknown, it has been proposed that aminophylline may modulate the brain's usual seizure threshold through blocking adenosine receptors. ${ }^{27}$

\section{Cardiac effects}

Tachycardia is a common dose-dependent side effect of aminophylline and oral theophylline. ${ }^{25}$ In adults, theophylline has been implicated in the development of serious atrial tachyarrhythmias. It is not clear to what extent this risk extends to the paediatric population.

\section{Vomiting}

Vomiting is a common adverse effect of aminophylline and theophylline. It can happen at any plasma concentration, but is more common at supratherapeutic levels. $^{25}$

\section{RCTS OF SALBUTAMOL (OR TERBUTALINE) AND AMINOPHYLLINE}

We identified RCTs that assessed the use of intravenous salbutamol, terbutaline or aminophylline in the paediatric population after searching the Cochrane register of controlled trials. The identified trials have been summarised in a series of tables (see online supplementary tables S1-3), and the main findings are outlined in the text below.

In three RCTs, intravenous salbutamol or terbutaline therapy have been compared with either placebo or nebulised treatment in a total of 130 children with acute asthma. Two of these $\mathrm{e}^{\mathrm{W} 1 \mathrm{~W} 2}$ were conducted in the emergency department (ED) and assessed the efficacy of a bolus of salbutamol, and one ${ }^{\mathrm{W} 3}$ assessed the efficacy of a terbutaline infusion in a paediatric intensive care unit (PICU) setting.

Only one trial ${ }^{\mathrm{W} 1}$ reported benefit with regards to the assessment of clinical severity. One trial showed no difference, and in one trial the outcome was not reported. No trials reported lung function outcomes. Neither of the trials conducted in ED reported the rates of admission to PICU. Length of hospital stay was improved in the group receiving intravenous salbutamol in one trial conducted in $\mathrm{ED},{ }^{\mathrm{W} 2}$ but was not reported in the other. ${ }^{\mathrm{W} 1}$ Two of these studies were included in a Cochrane review, ${ }^{28}$ which concluded that there was very little evidence to support the addition of intravenous salbutamol to nebulised therapy in children with acute asthma exacerbations.

Aminophylline has been compared with placebo or usual treatment (one study compared a control group who were managed with continuous nebulised albuterol, inhaled ipratropium and intravenous methylprednisolone with an aminophylline group given the above plus intravenous aminophylline) in children with acute asthma exacerbations in 12 RCTs involving 586 children. ${ }^{\text {W4-15 }}$ Three were conducted in ED, seven on hospital wards, one on PICU and in one study reported as a conference abstract the setting was unclear.

Three trials found that aminophylline improved clinical severity scores, but six did not. Three trials did not report this outcome. Two trials showed improved lung function scores, two did not and eight did not report this outcome. One trial showed that aminophylline reduced PICU admission rates, but 
none of the other studies reported any results for this outcome. No trials have found any benefit of aminophylline on length of hospital or PICU stay (seven found no difference, and five did not report this outcome). Also, 7 of these 12 trials have been included in a Cochrane review. ${ }^{29}$ The review concluded that intravenous aminophylline improved lung function within $6 \mathrm{~h}$ of treatment, but did not appear to reduce symptoms or length of hospital stay, and there was insufficient evidence to evaluate its impact on PICU rates.

Intravenous aminophylline and salbutamol (or terbutaline) have been compared, head-to-head, in four RCTs involving 202 children. ${ }^{\text {W16-19 }}$ Two were conducted in hospital wards, and one in PICU. In one RCT, reported as a conference abstract, the setting was unclear.

In the three trials that reported results for clinical severity scores, there was no difference between salbutamol and aminophylline. No studies reported lung function outcomes. In the one study reporting PICU admission rates, there was no difference between aminophylline and salbutamol. In two studies reporting length of hospital stay, there was no difference between groups, and in two studies this outcome was not reported. These paediatric studies have been included in a subgroup analysis in a Cochrane review. ${ }^{30}$ The review concluded that there was no consistent evidence to help decide between aminophylline and salbutamol as the first-line intravenous therapy of choice.

It is difficult to draw clear conclusions from RCTs about the relative safety profiles of the two treatments. There is wide variability in the assessment and reporting of adverse effects associated with the two treatments in clinical trials. It would appear that salbutamol does carry a risk of cardiovascular adverse effects. In one study, ${ }^{\mathrm{W} 3} 6 / 25$ children treated with terbutaline had raised troponin-I levels and one was withdrawn because of arrhythmia. In one trial comparing salbutamol with aminophylline, the group receiving salbutamol demonstrated a significant trend towards tachycardia. Nausea and vomiting were the most commonly reported adverse effects associated with the use of intravenous aminophylline, as demonstrated in several trials and in a Cochrane review. ${ }^{29}$ In the trials involving intravenous aminophylline assessed for this review, there was only one reported case of a seizure.

\section{SUMMARY}

Salbutamol and aminophylline cause bronchodilation in airways of children with exacerbations of asthma. Both agents probably work by inducing the c-AMP pathway, which reduces intracellular calcium concentrations, thereby relaxing airway smooth muscle.

\section{Multiple choice questions}

1. Which process is not a factor in the pathophysiology of an acute exacerbation of asthma?
A. bronchoconstriction
B. vasoconstriction
C. mucus formation
D. inflammation
E. mast cell degranulation.

2. Which effect has not been suggested as a potential mechanism of action for aminophylline?

A. bronchodilation through inhibition of airway smooth muscle cell phosphodiesterases and subsequent increases in intracellular c-AMP concentrations;

B. bronchodilation via blockade of pulmonary adenosine receptors;

C. reduction of eosinophil activity in bronchial mucosa;

D. reduction of mucosal secretions through inhibition of epithelial sodium transporter channels;

E. inhibition of histones required for activation of inflammatory gene transcription.

3. Which adverse effect is not associated with the use of intravenous salbutamol?
A. lactic acidosis
B. hypokalaemia
C. tremor
D. myocardial ischaemia
E. hyponatraemia.

4. Which adverse effect is not associated with the use of intravenous aminophylline?
A. seizures
B. nausea
C. hypertrichosis
D. tachycardia
E. headache.

5. Which statement is true?

A. Aminophylline has a narrow therapeutic index, but reliable serum levels can always be achieved by following recommended dosing guidelines.

B. If adverse effects occur with the use of intravenous aminophylline, the serum levels will be above the recommended limits.

C. If serum theophylline levels are below the advised limits, the rate of the infusion should be increased immediately.

D. If a patient takes oral theophylline, they should not receive a loading dose of intravenous aminophylline.

E. The ethylenediamine compounds attached to theophylline in order to make aminophylline are thought to contribute to its bronchodilatory effects.

Answers are on page 222. 
Aminophylline may have additional mechanisms of action, which are poorly understood. Both agents also have extrapulmonary adverse effects, which can be dangerous or distressing to children.

The evidence from RCTs for the intravenous administration of either drug to children during an asthma exacerbation is minimal and inconsistent. A bolus of intravenous salbutamol may reduce symptoms and hasten recovery. ${ }^{\mathbb{W}}$ Aminophylline infusions may improve lung function, and in some studies have been shown to improve symptoms, but this finding is not replicated in all studies. It is unlikely that either agent reduces PICU admission rates or length of hospital stay, but these evaluations are hampered because many studies do not report these outcomes. Adverse effects were noted with the use of both treatments, but the available evidence does not enable comparison of the likelihood of adverse effects with either treatment.

Despite the minimal evidence of benefits from RCTs, intravenous therapy probably does have a role in managing certain children with either refractory or severe exacerbations of asthma, and those who have previously required PICU admission. Variation of practice at individual clinician and departmental level is likely to continue with regards which of these agents should be used first. Given that intravenous agents are likely to remain in widespread use, we suggest that the choice should take into account factors such as ease of prescription, preparation and administration (which have direct implications for risk management), availability of high-dependency beds and nursing preference. These factors are summarised in table 1.

Whichever therapy is used, we would advocate that children are assessed for objective markers of improvement of clinical status after the initial loading dose bolus to evaluate whether they really need to be treated with a subsequent infusion or not. We would also stress the importance of stringent, routine monitoring of the adverse effects that we have highlighted. Current uncertainty about these therapies, including guidelines on how drug levels and adverse effects should be monitored in children, must be addressed in future research studies.

Contributors The original idea for this article came from IS, who suggested a review of the evidence around the use of intravenous salbutamol and aminophylline focusing on their mechanisms of action, efficacy and safety. The literature search and suggestions for subheadings within the pharmacology sections came from MN, OA and RF. The literature search for randomised control trials was conducted by IS and MN. The tables in the online supplementary file were produced by $\mathrm{MN}$. The first draft of the article was produced by $\mathrm{MN}$ and was edited by IS after discussion between all the authors. IS is the guarantor for the paper.

\section{Competing interests None.}

Provenance and peer review Commissioned; externally peer reviewed.

\section{REFERENCES}

1 Holgate ST. Pathogenesis of Asthma. Clin Exp Allergy 2008;38:872-97.

2 Rowe BH, Bretzlaff J, Bourdon C, et al. Magnesium sulfate for treating exacerbations of acute asthma in the emergency department. Cochrane Database Syst Rev 2000;(2):CD001490.

3 Lyttle MD, O'Sullivan R, Doull I, et al. Clinician variation in treating childhood wheeze in Emergency Departments of the United Kingdom and Ireland-an international survey. Arch Dis Child 2014;99:S1 A2.

4 Johnson M. Beta-2 adrenoceptors: mechanisms of action of Beta-2 agonists. Paediatr Respir Rev 2001;2:57-62.

5 Barnes PJ. Theophylline. In: Barnes PJ, Drazen JM, Rennard $\mathrm{SR}$, et al., eds. Asthma and COPD; basic mechanisms and clinical management. 2nd edn. San Diego, CA: Academic Press, 2009:536.

6 Barnes PJ. New drugs for asthma. Nat Rev Drug Discov 2004;3:831-44.

7 Starkey ES, Mulla H, Sammons HM, et al. Intravenous salbutamol for childhood asthma: evidence-based medicine? Arch Dis Child 2014;99:873-7.

8 Aherns C, Smith G. Albuterol:an adrenergic agent for use in the treatment of asthma pharmacology, pharmacokinetics and clinical use. Pharmacotherapy 1984;4:105-20.

9 Bremmer P, Woodman K, Burgess C, et al. A comparison of the cardiovascular and metabolic effects of formoterol, salbutamol and fenoterol. Eur Respir J 1993;6:204-10.

10 Haffner CA, Kendall MJ. Metabolic effects of beta-2 agonists. J Clin Pharm Ther 1992;17:155-64.

11 Neville A, Palmer J, Gaddie J, et al. Metabolic effects of salbutamol: comparison of aerosol and intravenous administration. Br Med J 1977;1:413-14.

12 Phillips PJ, Vedig AE, Jones PL, et al. Metabolic and cardiovascular side effects of the B2-adrenoceptor agonists salbutamol and rimiterol. Br J Clin Pharmacol 1980;9:483-91.

13 Prakash S, Mehta S. Lactic acidosis in asthma: report of two cases and review of the literature. Can Respir J 2002;9: 203-8.

14 Badar MG, Hughes R. An unusual case of Lactic Acidosis. BJMP 2011;4:420.

15 Yim RP, Koumbourlis AC. Tolerance \& resistance to b2-agonist bronchodilators. Paediatr Respir Rev 2013;14:195-8.

16 Church MK, Featherstone RL, Cushley MJ, et al. Relationships between adenosine, cyclic nucleotides, and xanthines in asthma. J Allergy Clin Immunol 1986;78:670-5.

17 Howell RE. Multiple mechanisms of xanthine actions on airway reactivity. J Pharmacol Exp Ther 1990;255:1008-14.

18 Poolson JB, Kazanowski JJ, Goldman AL, et al. Inhibition of human pulmonary phosphodiesterase activity by therapeutic levels of theophylline. Clin Exp Pharmacol Physiol 1978;5:535-9.

19 Barnes PJ. Theophylline: new perspectives for an old drug. Am J Respir Crit Care Med 2003;167:813-18.

20 Cushley MJ, Tattersfield AE, Holgate ST. Adenosine-induced bronchoconstriction in asthma: antagonism by inhaled theophylline. Am Rev Respir Dis 1984;129:380-4.

21 Sullivan P, Bekir S, Jaffar Z, et al. Anti-inflammatory effects of low-dose oral theophylline in atopic asthma. Lancet 1994;343:1006-8.

22 Yasui K, Agematsu K, Shinozaki K, et al. Theophylline induces neutrophil apoptosis through adenosine A2A receptor antagonism. J Leukoc Biol 2000;67:529-35. 
23 Ito K, Lim S, Caramori G, et al. A molecular mechanism of action of theophylline: induction of histone deacetylase activity to decrease inflammatory gene expression. Proc Natl Acad Sci USA 2002;99:8921-6.

24 Baker MD. Theophylline toxicity in children. J Pediatr 1986;109:538-42.

25 Powell EC, Reynolds SL, Rubenstein JS. Theophylline toxicity in children: a retrospective review. Paediatr Emerg Care 1993;3:129-33.

26 Yoshikawa H. First-line therapy for theophylline-associated seizures. Acta Neurol Scand Suppl 2007;186:57-61.

27 Boison D. Methylxanthines, seizures and excitotoxicity. Handb Exp Pharmacol 2011;200:251-66.

28 Travers AH, Milan SJ, Jones AP, et al. Addition of intravenous beta 2-agonists to inhaled beta 2-agonists for acute asthma. Cochrane Database Syst Rev 2012;12:CD010179.
29 Mitra AAD, Bassler D, Watts K, et al. Intravenous aminophylline for acute severe asthma in children over two years receiving inhaled bronchodilators. Cochrane Database Syst Rev 2005;(2):CD001276.

30 Travers AH, Jones AP, Camargo CA Jr, et al. Intravenous beta2-agonists versus intravenous aminophylline for acute asthma. Cochrane Database Syst Rev 2012;12:CD010256.

\section{Answers to the multiple choice questions}

1. B

2. $D$

3. $\mathrm{E}$

4. C

5. D 